\title{
Exploration and Practice on Stimulation of Students' Interests in Theoretical Physics Courses
}

\author{
Yi Jin* \\ Department of Physics \\ University of Jinan \\ Jinan, P.R. China \\ ss_jiny@ujn.edu.cn
}

\author{
Shi-Yuan Li \\ School of Physics \\ Shandong University \\ Jinan, P.R. China \\ lishy@sdu.edu.cn
}

\begin{abstract}
How to stimulate university students' interests in studying theoretical physics courses is a general question for most universities. Taking electrodynamics as an example, we bring out and illustrate four relevant ways in detail, which are teaching guidance for each knowledge point, notice on physical images, extensive discussions inside and outside classroom, and use of various media to guide interests. The above methods are based on the authors' teaching practice and have been proved to be working. Our exploration and discussion may provide the reference for the colleagues of physics teachers in colleges and universities.
\end{abstract}

Keywords - theoretical physics; electrodynamics; study interest; combination of theoretical content and practice

\section{INTRODUCTION}

As is well-known, the main courses involved in curriculum system of theoretical physics in colleges and universities are mathematical physics methods, theoretical mechanics, thermodynamics and statistical physics, electrodynamics and quantum mechanics. In addition to laying a good physical foundation systematically for students, the above courses also shoulder the important task of cultivating scientific thinking ability and stimulating innovation spirit for students. In recent decades, the rapid development of high and new technology has attracted much attention in applied physics, and theoretical physics seems to be out of date. Here people appear to ignore or forget that almost all applied physics and its associated high and new technologies are based on theoretical physics. However, most college students majoring in physics often feel nothing about it. This is indeed a serious flaw in physics, especially in theoretical physics teaching [1]. The fundamental reason lies in the fact that the traditional theoretical physics teaching emphasizes theory explanation and formula derivation, which often makes students feel boring and even misunderstand that theory has no practicability. Therefore, theoretical physics is recognized by teachers and students as "difficult to learn and difficult to teach". The overall teaching effect is not satisfactory. This is also a problem faced by other science and engineering theoretical courses. How to make the students not to ignore the fundamental and importance of theoretical physics, that is, how to fully reflect the "application" value of "theoretical" physics is the requirement of the training goal of "unity of knowing and practice" of the

This article is supported by the following funds: Quality Course Construction of Colleges and Universities in Shandong Province (JPKC201311), Quality Course Construction of Shandong Province Graduate Education (1907319). physical professionals.

In fact, taking electrodynamics as an example, the maturation of electrodynamics has promoted the rapid development of modern science and technology. There are a large number of problems related to electrodynamics in astrophysics, particle accelerators, daily office and household appliances. Especially since this century, the production practice has put forward many new demands on the electromagnetic properties of materials, which makes the electrodynamics in the meantime of facing the challenge of new subjects, has also gained a wider development opportunity on the basis of combining with other disciplines. Therefore, electrodynamics learning is of great practical significance. Zakov, a famous educationalist, once said that interest in learning knowledge may become a learning motivation. One of the most fundamental and effective ways to develop quality education and optimize classroom teaching is to fully stimulate students' interests in learning.

\section{FOUR WAYS FOR STUDENTS' INTERESTS STIMULATION}

In the following, we shall bring out four ways for the stimulation of students' interests, which are from the summaries of practice experiences in the daily electrodynamics teaching. We hope that the vast majority of colleagues can refer to them and give us corrections.

\section{A. Doing Well in Teaching Guidance for Each Class and Each Knowledge Point}

"Everything is difficult at the beginning," and "a good beginning is half done." The introduction of teaching in every class is like the "Introduction" in music, which plays a role in brewing emotions, permeating themes and bringing into situations [2]. Only by carefully designing the stage of classroom guidance can teachers grasp the students' heartstrings, promote their emotional upsurge, and lead them step into the state of knowledge-seeking exhilaration. For the beginning of each class, and even every knowledge point, the teacher should try to set up the suspense, and adjust the students' learning emotion, attention and thinking activity to a positive state. For example, at the beginning of the Chapter of "Propagation of electromagnetic waves" of electrodynamics, we can introduce a series of interesting examples of electromagnetic wave applications, such as why microwave oven can heat food evenly, why the desk surface is very bright 
while we look at it slanting, why the F117 fighter can provide invisibility, and why the optical fibers can transmit information.

These multi-directional examples can not only make students feel that the complex theory of electrodynamics is very close to their own life, but also make them believe that the theory can be converted into the possibility of technology application. In guiding students, we can "play hard to get", that is, the teacher do not explain the questions in detail first, and then stimulates students to produce the curiosity of "after all reason". They will spontaneously seek the answers in their studies and gain a sense of achievement. It should be noted that the techniques of guiding can be varied flexibly, and the design needs to be reasonably arranged according to the content of different knowledge.

\section{B. Pay Attention to the Explanations of Physical Image and Memory Rule of Physical Formula}

The concepts and laws in electrodynamics are abstract, with numerous formulas and complicated derivations. This is the main reason that makes students feel dull and difficult to produce interests in learning. For example, the boundary value relationship of electromagnetic fields is one of the foundations of electrodynamics besides the Maxwell equations. The memory and derivation of the corresponding formulas is always a headache for most students. Hence when explaining this part, teachers should pay special attention to the means of imparting the knowledge, and should not blindly teach tedious mathematical derivation. Especially in memory method, we can guide students to find a type of ingenious substitutions of $" \nabla \rightarrow n, \partial / \partial t \rightarrow 0$, field quantity $\rightarrow 2-1$, body density $\rightarrow$ surface density $\rightarrow$ line density" in Maxwell differential equation to easily get every kind of boundary value relationships. In this way, students can not only lighten their burden of studies, but also develop the habit of analyzing questions step by step, abandon rote memorization and then train their memories of physics formula by understanding.

\section{Extensive Discussions, Explorations and Summaries inside and outside Classroom}

The teaching method must touch the students' emotional field and the spiritual needs in order to play a highly effective function. In the information age, the Internet, television and other media can be seen everywhere, thus people can easily obtain a large number of scientific and technological knowledge through multiple channels. College students are important carriers and disseminators of modern science and technology knowledge. They have a strong sense of subject consciousness and responsibility of the era, and are thirsty for knowledge. They are not satisfied with simple understanding in acquiring new knowledge, but desire to be deeper, more accurate, more scientific than the general public, and thus gain approval and reorganization from others.

In both the classroom and life practice, students will inevitably find some questions or doubts that are related to the classroom knowledge, which are generally in the flash, soon will be left behind. Teachers should remind students to grasp the problem and write them down, and then they can discuss them once they have a certain basic knowledge. Of course, teachers can also actively arrange some small topics in the classroom, and these topics need not be of great significance or scientific value, and even contents that are not discussed in detail in a book can be. For these subjects, it is not necessary for students to conduct in-depth research in scientific research. After all, it is unrealistic for most students. As long as students can try to write down a research or summary report, they can achieve the basic scientific research quality and improve the thinking method of quality education purposes. In this way, once students succeed in their own studies, they will have a strong interest in learning [3].

In addition, teachers can use the forms of speech, questioning and discussion to promote the lively and orderly interactive teaching when the time is allowed. It is not only teachers but also students who can stand on the podium; not only the teachers ask the students questions, but also the students can ask the teachers; but the students ask questions from the students, either teachers or students; the person who answers the question can be a teacher or a student. This lively and free teaching form can not only help students understand the content of knowledge, but also develop their personal potentials and enhance their adaptability and viability after entering the society.

\section{Keep Pace with the Times and Use Various Media to Guide Students' Interests}

Modern college students are used to getting information and entertainment from a variety of media, such as rich internet or colorful movies. They are no longer satisfied with the monochromatic color of black-and-white in the classroom. Teachers should find out and master this general psychology of students. In addition to using conventional means such as multimedia animation and demonstration, teachers can also introduce some healthy and relevant film clips relevant to the teaching contents. These auxiliary methods will make students learn easily and make them impressed and memorable about what they have learned.

For example, the popular "Youku" video network (www.youku.com) has many small videos relate with electrodynamics, such as maglev trains, biological electromagnetic waves and so on. In Hollywood films, the clips concerned the electromagnetic effects are innumerable, such as the cessation of the earth's core in the movie "The Core" which causes a sudden disintegration of the earth's electromagnetic fields to abnormal calamities around the world; the submarine uses electromagnetic force to ionize seawater and push it back into the sea in "The Hunt for Red October"; the heroine in "Hollow Man" wrapped the wire around the iron handle and made the electromagnet in order to escape from the freezer...... The above videos reproduce vivid and interesting situations related to the knowledge of electrodynamics.

\section{The Combination OF TheORETiCAl CONTENTS AND REALITY}

While selecting the classical teaching contents, we should constantly enrich the latest achievements of the development of science and technology into the courses [4], for example, the magnetic field and origin of celestial bodies, electromagnetic 
properties of nanomaterial, principle and use of synchrotron accelerator, new magnetic materials, electromagnetic fields in plasma, photonic crystals, superconducting materials, and the recent Nobel physics prize about GMR effect, optical fiber theory and CCD, etc.

In addition, as far as the physics teaching of the undergraduate stage is concerned, the experiment is the best embodiment of theory and practice combination, and it is also the most important link to train students' practical ability and innovation ability. But the survey found that compared with the developed countries, the experimental and theoretical teaching in many uni versities in China are not closely integrated, and the role of the experiment has not been brought into full play [5]. The core of scientific quality education is to cultivate students' practical ability and innovative spirit. Therefore, combining the two relatively independent systems of physical experiment teaching and theoretical teaching is the focus of the current teaching reform and the inevitable requirement of the times. In our teaching practice in recent years, we actively try to introduce flexible and diverse experiments into theoretical physics courses such as electrodynamics, which greatly arouses students' interests and enthusiasm in learning. For example, among modern physics experiments, we have carefully selected three experiments: "measurements of electrical and temperature characteristics of high temperature superconducting materials", 'transmission characteristics and basic measurements of microwave", and "measurements of Light Velocity by beat frequency". They are closely integrated with the theoretical contents of the course and have scientific frontier and extensive applications. In the experiments, students are encouraged to carry out innovations on the basis of existing instruments. Students' experimental results are counted as peacetime scores. This measure enabled them to get practical training outside the theory and deepened their understanding of the theories. Therefore, it obtains the students' general praise and positive response.

\section{Matters to Be Paid Attention}

In the process of arousing students' interests, we should also pay attention to the following points:

1) Modern university students are well-informed, teachers should be closely related to the actual life in the design, in order to attract students ' attention and arouse the sense of identity.

2) The classroom atmosphere of the theoretical courses should be as active as possible to break the lethargic situation. But a lively atmosphere is not an end but a means. Teachers' metaphors and examples should be appropriate, and they should not be sensationalism for the sake of a lively atmosphere, thus losing the scientific and strict nature of knowledge.

3) Teachers should improve their personal connotation, pay attention to knowledge accumulation in peacetime, and learn more about the development of other related disciplines and science and technology at ordinary times, so as to make the teaching contents rich and novel.

\section{DeVelopments of theoretical Physics Teaching ABROAD}

In fact, the dilemma of theoretical physics teaching cannot be entirely attributed to its own abstract and profound objective factors. There are still many disadvantages in subjective factors concerned teaching thought and teaching method. At present, the teaching mode of theoretical physics is generally single, which adopts the traditional teaching mode of infusion and pays attention to the theoretical derivation. It is suitable for transmission of knowledge, but lacks the intuitiveness and inspiration that teaching should have, rarely involves frontier fields, is out of touch with reality, and does not pay attention to the cultivation of ability. Therefore, the students' learning initiative and personality are restrained. Looking abroad, we can easily find that the changes and developments in theoretical physics teaching abroad in the last 30 or 40 years are quite striking, which is mainly embodied in the following aspects:

1) The starting point of teaching material is greatly improved, and the depth and difficulty are far beyond our existing textbooks. The corresponding contents are more extensive and include the knowledge closely related to scientific research, production and lives, which makes people refreshing [6].

2) The basic concepts and theories are only briefly introduced, with a large number of examples that have been analyzed and solved in detail and are closely related to reality as the main line. Therefore, the real realizations of "fine explanation and more practice" not only greatly broaden the students ' horizons and ideas, but also cultivate students' ability to think and solve problems independently.

3) Some exercises require students to use computer to solve, so that students' computer knowledge and programming ability can be tested and have the opportunity of practical application.

All above are incomparable to the current theoretical physics teaching in our country. Due to the limitation of the traditional syllabuses and the number of studying hours, the courses of theoretical physics in domestic universities often come to an end just after the basic theoretical framework has been set up, and the contents concerned applications and new achievements in physics are rather poor, which does not reflect the power of theoretical physics in cultivating methods of scientific thinking and abilities of solving practical problems. As a result, most students report not only that it is very hard to learn, but also that they do not know what the use is. Therefore, theoretical physics teaching needs to reform the old teaching modes, explore a new way to overcome the disadvantages and get out of the predicament.

\section{SUMMARY}

In a word, on the question of how to effectively reform the teaching mode of theoretical physics course, general physics teachers should actively think and explore. Interest is the best teacher. If students are interested, they will be eager to be active. Teachers should do their best to show students a wider range of knowledge so as to enhance students' interests in learning, which can enable students to receive knowledge effectively in a limited time, help them to truly understand the 
"beauty" and "application" of theoretical physics, and then greatly improve students' innovative spirit.

\section{REFERENCES}

[1] J.H. Wu, "Study on methodologies of innovation education in modern physics," Journal of Henan Institute of Education(Natural Science Edition) Zhengzhou, vol. 25, No. 2, pp. 70-72, June 2016 (In Chinese).

[2] H.Q. Liu, "Discussion on the application of classroom introduction in physics teaching," Education Teaching Forum Shijiazhuang, vol. 17, pp. 77-78, June 2012 (In Chinese).

[3] Y. Wan, S.D. Li, Y.M. Jin, and M.J. Liu, "Research on teaching methods for electrodynamics curriculum," Modern Educational
Technology Beijing, Vol. 25, No. 9, pp. 122-126, September 2015 (In Chinese).

[4] P.Y. Gui, "Research on the modernization and novelty of physics education teaching," Chinese science and technology review Beijing, Vol. 39, pp. 217-217, April 2014 (In Chinese).

[5] Q.L. Wang, H.F. Ren and L.M. Wang, "Investigation and survey on the teaching status of theoretical curriculum physics," Journal of Lanzhou University of Arts and Science(Natural Science Edition) Lanzhou, Vol. 27, No. 2, pp. 100-102, March 2013 (In Chinese).

[6] Y. Wan, S.O. Chen, X. Sun, Y.M. Jin, and M.J. Liu, "Comprehensive reform on theoretical physics curriculum group teaching methods by from point to overall Model,” Modern Educational Technology Beijing, Vol. 23, No. 12, pp. 123-125, December 2012 (In Chinese). 